\section{Stent-in-stent technique and endoscopic resection of granulation tissue to remove a migrated metal duodenal stent embedded in the colon}

Self-expandable metal stents (SEMSs) can be used to treat malignant gastroduodenal obstructions. In such cases, the incidence of stent migration is $5 \%$ and, if it occurs, surgery may be required [1]. We report a case with a migrated duodenal SEMS that had become embedded in the wall of the ascending colon.
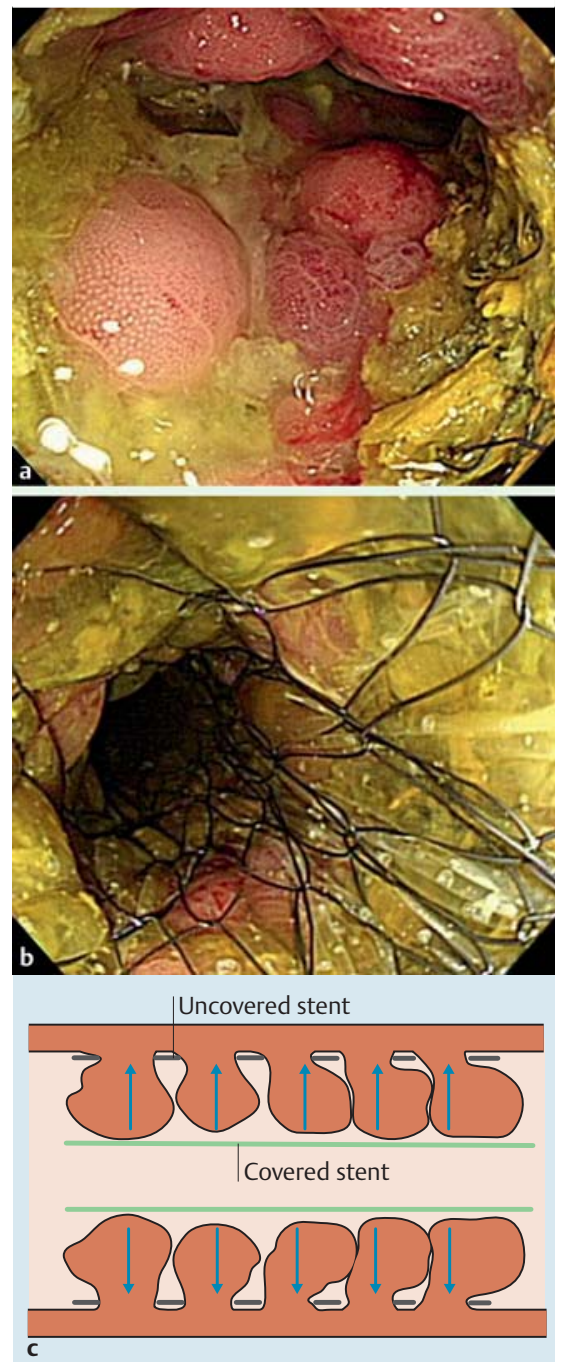

Fig. 1 a Colonoscopy showed a stent embedded in the ascending colon, with severe edema and inflammatory changes of the colonic mucosa. b A fully-covered stent was inserted through the migrated stent. c The schematic shows how colonic tissue trapped in the mesh of the uncovered stent was pushed back by the force (arrows) of the expanding covered stent.
A patient with gastric adenocarcinoma at the antrum that had invaded the pancreaticoduodenum received an uncovered SEMS (120-mm length, 20-mm diameter; S\&G Medical, Seoul, Korea). He attended the emergency room 11 days later because of abdominal pain. Computed tomography (CT) showed the stent had
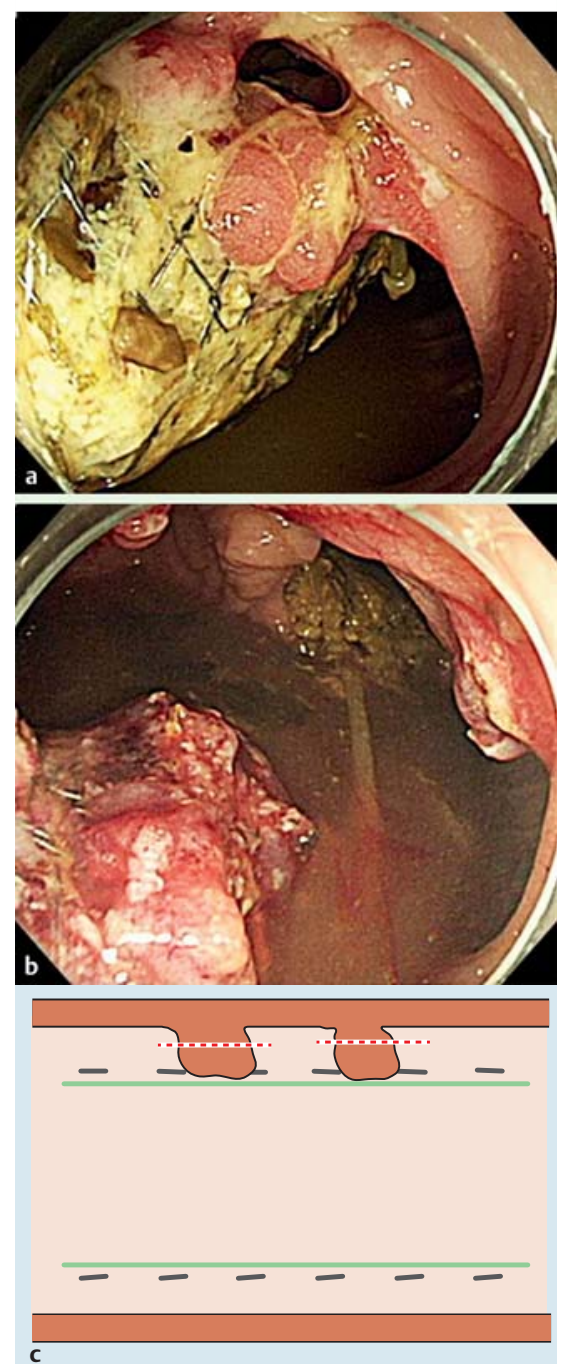

Fig. 2 Repeat colonoscopy 19 days after insertion of the covered stent. a The stents were attached to the colonic wall only by peduncles of granulation tissue. $\mathbf{b}$ The appearance after the stents had been completely separated from the colonic wall by cutting the peduncles using the tip of a snare. $\mathbf{c}$ Schematic showing the stents suspended from the colonic wall by peduncles of granulation tissue, which were cut as indicated by the red dashed lines. migrated into the ascending colon, but there was no evidence of colonic perforation. Colonoscopy revealed that the stent was tightly embedded in the wall of the colon, with inflammatory changes present in the mucosa ( Fig. 1 a). So that the stent could be separated from the colonic wall, a fully-covered stent (120-mm length, 24-mm diameter; S\&G Medical) was inserted using the stent-in-stent technique $(\bullet$ Fig. 1 b,c).

Repeat colonoscopy 19 days later showed the stents remained attached to the colon only by peduncles of granulation tissue ( Fig. 2a). The peduncles were cut using the tip of a snare and Endocut Q mode (ef-
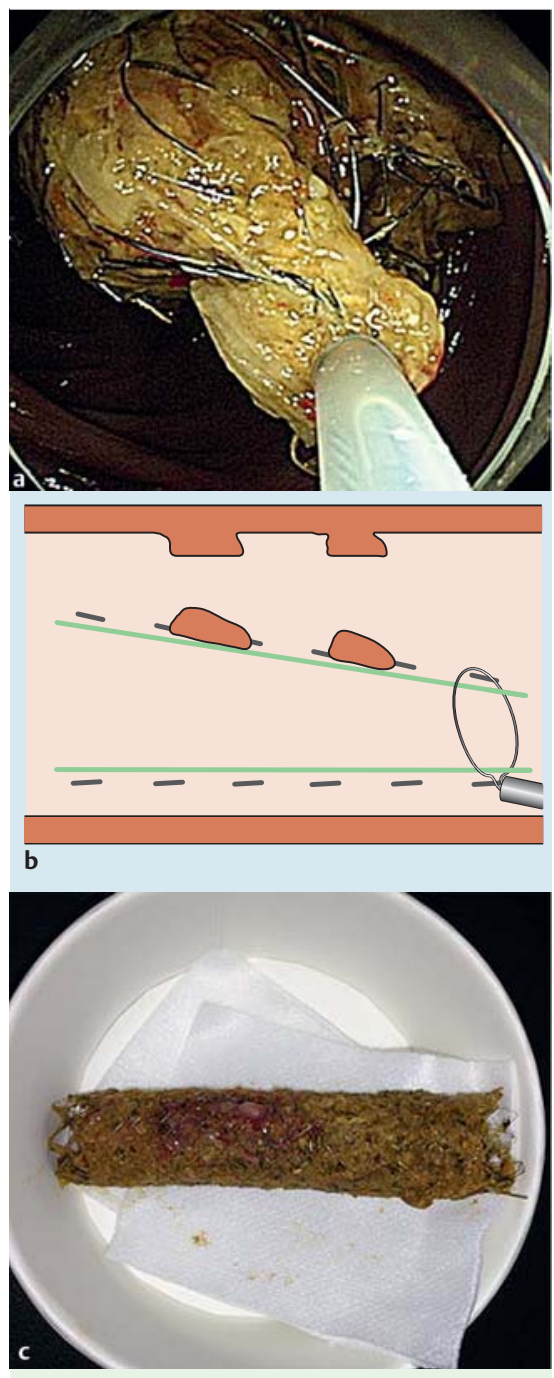

Fig. 3 a Colonoscopic view of the distal end of the stents being grasped with a snare. b Schematic of the maneuver in part $\mathbf{a}$. c The stents that were removed from the colon. 
fect 3, cut duration 2 seconds, cut interval 6 ) of an electrosurgical unit (VIO 300D; ERBE, Tübingen, Germany; ( Fig. $\mathbf{2 b}$ b; - Video 1). The stents were gently removed by grasping their distal ends with the snare ( Fig.3). The procedure time from scope insertion to stent removal was 23 minutes. The patient had no immediate or long-term complications.

The stent-in-stent technique has been used previously to remove SEMSs embedded in the esophagus or biliary tract [24]. A SEMS embedded in the colon was removed using a dual-channel endoscope and two rat-tooth forceps following the stent-in-stent technique [5]. We easily removed this stent that was embedded in the ascending colon using the stent-instent technique, which was followed by endoscopic resection of the remaining peduncles of granulation tissue.

\section{Video 1}

A metal duodenal stent, which had migrated and become embedded in the ascending colon, is successfully removed using the stent-in-stent technique and subsequent endoscopic resection of the granulation tissues.
Endoscopy_UCTN_Code_TTT_1AQ_2AH

Competing interests: None

\section{Dong-Hoon Yang, Myeongsook Seo, Hyo Jeong Lee, Sang Hyoung Park, Kyung-Jo Kim, Byong Duk Ye, Jeong-Sik Byeon, Seung-Jae Myung, Suk-Kyun Yang}

Department of Gastroenterology, Asan Medical Center, University of Ulsan College of Medicine, Seoul, Korea

\section{References}

1 Dormann A, Meisner S, Verin $N$ et al. Self-expanding metal stents for gastroduodenal malignancies: systematic review of their clinical effectiveness. Endoscopy 2004; 36: $543-550$

2 Hirdes MM, Siersema PD, Houben MH et al. Stent-in-stent technique for removal of embedded esophageal self-expanding metal stents. Am J Gastroenterol 2011; 106: 286 293

3 Tan DM, Lillemoe KD, Fogel EL. A new technique for endoscopic removal of uncovered biliary self-expandable metal stents: stentin-stent technique with a fully covered biliary stent. Gastrointest Endosc 2012; 75: 923-925
4 González N, Ramesh J, Wilcox CM et al. Endoscopic removal of an impacted bile duct selfexpanding metal stent (SEMS) using the SEMS-in-SEMS technique. Endoscopy 2013; 45: E254-E255

5 Gornals JB, Golda T, Soriano A. Stent-in-stent technique for removal of a metal stent embedded in the colon wall by using a fully covered, self-expandable metal esophageal stent (with video). Gastrointest Endosc 2012; 76: 695-696

\section{Bibliography}

DOI http://dx.doi.org/

10.1055/s-0034-1365114

Endoscopy 2014; 46: E159-E160

(c) Georg Thieme Verlag KG

Stuttgart · New York

ISSN 0013-726X

\section{Corresponding author}

\section{Dong-Hoon Yang, MD, PhD}

Department of Gastroenterology University of Ulsan College of Medicine

Asan Medical Center

88, Olympic-ro 43-gil

Songpa-gu

Seoul, 138-736

Korea

Fax: +82-2-30106517

dhyang@amc.seoul.kr 